\title{
Epidemiology of familial sarcoidosis in the UK
}

\author{
D S McGrath, Z Daniil, P Foley, J L du Bois, P A Lympany, P Cullinan, R M du Bois
}

\begin{abstract}
Background-The last comprehensive epidemiological studies on familial sarcoidosis in the UK were more than 25 years ago, reporting another affected family member in $1.7 \%$ of index cases. A significant proportion of like-sex over unlike-sex pairs, an excess of mother-child over father-child associations, and a preponderance of monozygous over dizygous twins was noted. Another study reported ethnic heterogeneity in familial disease. This study was undertaken to identify the risk ratio $\left(\lambda_{s}\right)$ for siblings of familial sarcoidosis in the UK, to determine if the previous epidemiological findings have persisted, and to reassess whether ethnic heterogeneity prevails in familial disease. Method-Questionnaires were sent to 406 index patients.
\end{abstract}

Results-Two hundred and sixty eight replies $(66 \%)$ were received. Twenty four of the original 406 index patients $(5.91 \%)$ were found to have at least one other relative (first, second or third degree) with biopsy proven sarcoidosis. A $\lambda_{s}$ value of 36-73 was calculated indicating significant familial clustering of the disease. Ethnically the families comprised $62.5 \%$ Caucasian, 29.2\% Afro-Caribbean, and 8.3\% Asian. Mean age at diagnosis was 39.8 years for women and 40.9 years for men with a male to female ratio of $1: 1.7$. This differed for the Asian families in which all the affected members were male. Three sets of female twins (two monozygous and one dizygous) were included. There was an equal distribution of like-sex (primarily female) and unlike-sex families as well as mother-child and father-child pairs. Pulmonary involvement was predominant irrespective of ethnicity, as was the need for corticosteroid treatment.

Conclusions-These results support the theory that a shared determinant (either genetic or environmental) is operating in familial sarcoidosis and suggest that this determinant is similar for all ethnic groups.

(Thorax 2000;55:751-754)

Keywords: epidemiology; sarcoidosis; risk ratio to siblings of a disease $\left(\lambda_{\mathrm{S}}\right)$

Sarcoidosis is a multisystem granulomatous disorder, the aetiology of which remains unknown. It has been conceived that, as in the case of beryllium induced lung disease, an environmental trigger/antigen initiates an immune mediated response in a genetically susceptible individual. Antigen presenting cells then process and present the antigen, in the context of class II HLA molecules, to helper CD4+ T-cells. ${ }^{1}$ This results in a cascade of lymphocytes and mononuclear phagocytes, recruitment and upregulation of cytokines and associated ligands that lead to granuloma formation and distortion of the normal microarchitecture of the organs involved. In sarcoidosis, unlike beryllium lung disease, the antigen has not yet been identified.

The basis to the theory that genetic factors may play a part in the predisposition to sarcoidosis dates back to the 1920s when the first cases of acute sarcoidosis in siblings were reported. ${ }^{2}$ There have been a number of reports of the prevalence of familial clustering in sarcoidosis ranging from $1.7 \%$ (UK), $4.7 \%$ (Finland), $4.3 \%$ (Japan), 9.6\% (Ireland) to $17 \%$ (African-Americans). ${ }^{3-9}$ In the UK report a total of nine families from a series of 537 patients were identified giving a prevalence of $1.7 \%$ for familial sarcoidosis. This study also showed a preponderance of monozygous over dizygous twins, like-sex over unlike-sex pairs, and mother-child over father-child associations in these families. Significantly, Rybicki et al described for the first time in 1996 variability of familial risk in US citizens with African Americans having a threefold increased risk of familial disease compared with controls. ${ }^{10}$

Recent advances in molecular genotyping have provided powerful tools with which to attempt to define more precisely the genetic factors that predispose to sarcoidosis. Furthermore, there has emerged an increased awareness of sarcoidosis in recent years, particularly the occurrence of the disease in more than one member of the same family.

Therefore, as a preface to employing our molecular genotyping approaches ${ }^{11} 12$ in familial sarcoidosis, the aims of this study were (1) to determine if the previous epidemiological findings have remained constant over time, (2) to update the prevalence of familial sarcoidosis in a UK population and to quantify familial risk by determining the relative risk to a sibling of an index case of developing the condition when compared with the risk in the normal population $\left(\lambda_{s}\right)$, and (3) to determine if ethnic heterogeneity prevails in familial disease in the $\mathrm{UK}$ as it does in the USA.

To achieve these goals we conducted a survey, in the form of a questionnaire, of 406 patients with sarcoidosis attending the Royal Brompton Hospital between 1990 and 1995.

\section{Methods}

PATIENTS AND QUESTIONNAIRE

The names and addresses of 406 index patients attending the Royal Brompton Hospital between the years 1990 and 1995
26 May 2000

Accepted for publication

2 June 2000 
Table 1 Sex distribution of Caucasian, Afro-Caribbean and Asian sarcoidosis families

\begin{tabular}{llll}
\hline & \multicolumn{2}{l}{ No. (\%) of families } & \\
\cline { 2 - 4 } & Caucasian & Afro-Caribbean & Asian \\
\hline Like-sex $(52 \%)$ & $6(50 \%)$ & $4(33.3 \%)$ & $2(16.7)$ \\
Female & $5(83.3 \%)$ & $3(75 \%)$ & $0(0 \%)$ \\
Male & $1(16.7 \%)$ & $1(25 \%)$ & $2(100 \%)$ \\
Unlike-sex (48\%) & $8(72.7 \%)$ & $3(27.3 \%)$ & $0(0 \%)$ \\
\hline
\end{tabular}

were sequentially accessed from the sarcoidosis database; $77 \%$ of these index patients had their diagnosis confirmed on biopsy while $23 \%$ were diagnosed on clinical and radiological features. A questionnaire was mailed to each of the 406 index patients. The format of the questionnaire was such that the patient had to indicate if one or more family members had sarcoidosis. If this was the case, the questionnaire was then to be completed by the affected relative(s) giving name, date of birth, age at diagnosis, hospital attended, method of diagnosis, system involvement, and treatment. This was then to be returned in a stamped addressed envelope. Any queries with regard to the questionnaire could be answered by telephone or in person with the patient/ relative. Permission to contact a relative's general practitioner (GP) if medical information (particularly biopsy information) was lacking was also obtained. In two cases questionnaires were completed for deceased affected relatives by a surviving family member and medical information was then confirmed with the individual's GP.

Ethical approval for the study was obtained from the ethics committee of the Royal Brompton \& Harefield NHS Trust and the National Heart \& Lung Institute.

RELATIVE RISK RATIO $\left(\lambda_{\mathrm{S}}\right)$

The relative risk ratio $\left(\lambda_{s}\right)$ to siblings of sarcoidosis was calculated using the method developed by Risch. ${ }^{13}$ Briefly, this is defined as the prevalence of the disease in siblings of an affected person/population prevalence for the disease. A large value for $\lambda_{s}$ indicates simple Mendelian disease (for example, $\lambda_{\mathrm{s}}=500$ in cystic fibrosis), usually fully penetrant and easily mapped, whereas a small value (for example, $\lambda_{\mathrm{s}}=8$ in rheumatoid arthritis) indicates more complex disease. The magnitude of the $\lambda_{\mathrm{s}}$ also indicates the degree of difficulty that will be involved in mapping a susceptible gene locus. In fact, if $\lambda_{S}$ (or $\lambda_{R}$, where $\mathrm{R}=$ relative) $<1.5$, one is very unlikely to identify a disease susceptibility gene. ${ }^{14}$ If $\lambda_{s}>10$ there is a significant likelihood that one or more important shared determinants are operating. ${ }^{15}$

Table 2 Ethnic distribution of organ involvement and disease severity in sarcoidosis families

\begin{tabular}{lccl}
\hline & \multicolumn{2}{l}{ No. (\%) of patients } & \\
\cline { 2 - 4 } & Caucasian & Afro-Caribbean & Asian \\
\hline Pulmonary & $26(86.7 \%)$ & $12(85.7 \%)$ & $4(100 \%)$ \\
Skin & $8(26.7 \%)$ & $1(8.3 \%)$ & $1(25 \%)$ \\
Ocular & $1(3.3 \%)$ & $3(25 \%)$ & $1(25 . \%)$ \\
Neurological & $1(3.3 \%)$ & $0(0 \%)$ & $0(0 \%)$ \\
Liver & $1(3.3 \%)$ & $1(8.3 \%)$ & $0(0 \%)$ \\
Lymph nodes & $3(11.5 \%)$ & $1(8.3 \%)$ & $0(0 \%)$ \\
Corticosteroids & $18(60 \%)$ & $11(78.6 \%)$ & $2(50 \%)$ \\
\hline
\end{tabular}

These determinants may be either environmental or genetic.

ETHNIC HETEROGENEITY

Population data for the various ethnic groups in both London and the UK was obtained from the National Statistics Office (1991 census).

STATISTICAL ANALYSIS

Statistical analysis was performed using the ANOVA one way (unstacked) analysis of variance and the Woolf-Haldane (Sigtest) analysis.

\section{Results}

QUESTIONNAIRE DATA

One hundred and five patients responded to the initial questionnaire. The questionnaire was then remailed to the remaining 301 patients. A total of 268 replies was received from the 406 questionnaires posted $(66 \%$ response rate). Of the original 406, 24 confirmed a positive family history of sarcoidosis giving a prevalence of $5.91 \%$. Complete epidemiological and medical data were available on 23 of these sarcoidosis families. Twenty two families had only two family members with sarcoidosis while one family had four affected relatives.

Twenty of the families comprised first degree relatives -15 sibling pairs and six parent-child associations (two of the latter came from the same family). Two families consisted of second degree relatives (two aunt/uncle-niece/nephew pairs) and one family of third degree relatives (one cousin pair). Of the 48 affected family members $41(85.4 \%)$ had biopsy proven disease while $14.6 \%$ (six Caucasian and one Afro-Caribbean) were diagnosed on clinical and radiological grounds.

EPIDEMIOLOGICAL DATA

From the 23 families three sets of twins, two monozygous and one dizygous, were observed. Mean ages at diagnosis for women and men were similar at 39.8 (range 21-59) years and 40.9 (range 29-57) years, respectively. When ethnic origin was taken into account no significant difference was found in these values. In addition, although the overall mean age at diagnosis of Caucasians appeared greater (43 (29-50) years) than that of Afro-Caribbeans and Asians (32.1 (21-59) and 35 (31-39), respectively), this was not statistically significant $(p=0.56)$. The male to female ratio was calculated at $1: 1.7$. This varied only for the two Asian families of which all four members were male. When the epidemiological data were further analysed, a similar percentage of like-sex $(52 \%, \mathrm{n}=12)$ and unlike-sex $(48 \%, \mathrm{n}=11)$ families was noted as well as mother-child $(17.4 \%, \mathrm{n}=4)$ and father-child $(13 \%, \mathrm{n}=3)$ pairs. A total of $66.7 \%(n=8)$ of the like-sex families were female (table 1).

Specific organ involvement was recorded for each individual (table 2). Pulmonary involvement was predominant in all three groups. Although eye involvement appeared more frequent in Caucasians than in AfroCaribbeans or Asians, this was not statistically 


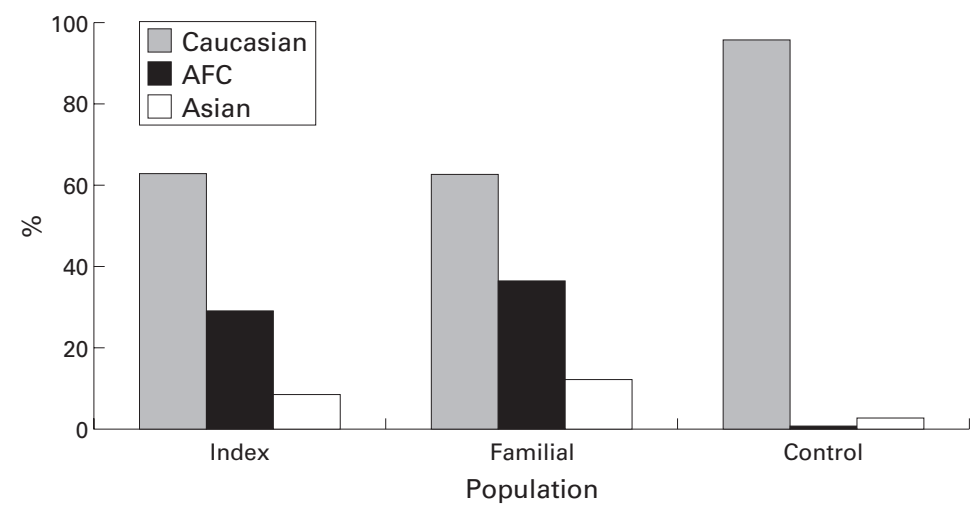

Figure 1 Comparison of ethnic distribution of index sarcoidosis patients, familial sarcoidosis patients, and a normal UK population.

significant ( $p=0.19$ and $p=0.9$, respectively). Finally, the proportion of patients receiving corticosteroid treatment (used as a marker of disease severity) was similar for all three groups when population size was taken into account (table 2).

RELATIVE RISK OF SARCOIDOSIS IN UK SIBLINGS There were a total of 38 siblings for the 15 index patients with an affected sibling. Using these numbers, we estimate a total of 1029 siblings for the base population of 406 cases. In this way the prevalence of sarcoidosis among siblings was estimated at $1.46 \%$. The UK sarcoidosis prevalence rate has been recorded as between $0.02 \%$ and $0.4 \% .{ }^{16}$ The risk ratio $\left(\lambda_{\mathrm{s}}\right)$ for siblings of patients with sarcoidosis of developing the disease (i.e. sibling prevalence/ population prevalence) was therefore determined to be between 36 and 73 . This result was confirmed using the Woolf-Haldane (Sigtest) analysis (sibling risk ratio $=38-75, \chi^{2}=$ $146-163, \mathrm{p}<0.005,95 \%$ confidence interval (CI) 21 to 145).

ETHNIC HETEROGENEITY

The index patients consisted of $62.2 \%$ Caucasians, $37.4 \%$ Afro-Caribbeans, and $11.8 \%$ Asians which was not significantly different from the proportions of the sarcoidosis families (62.5\% Caucasians, $29.2 \%$ Afro-Caribbeans, and $8.3 \%$ Asians). Index patients with sarcoidosis were four times less likely to be Caucasian $(\mathrm{p}<0.001$, relative risk $(R R)=0.23$, $95 \% \mathrm{CI}=0.19$ to 0.28 ) and three to four times

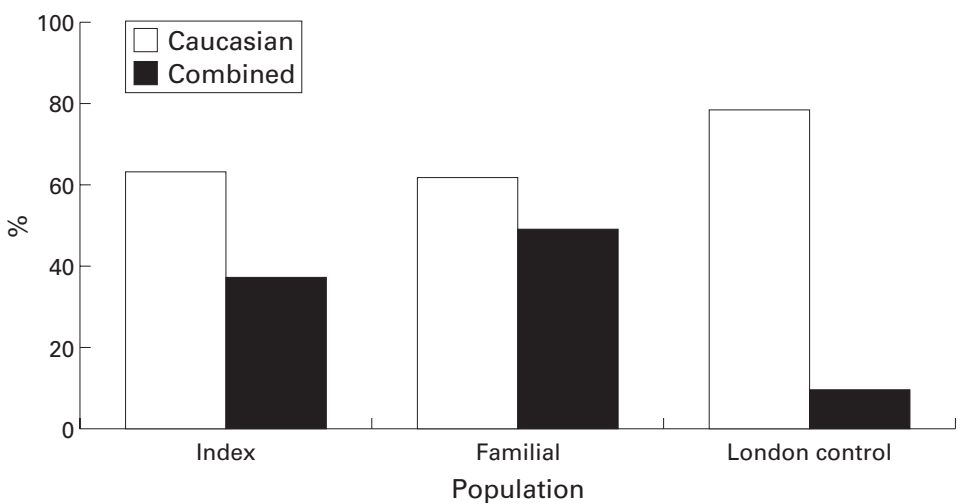

Figure 2 Comparison of ethnic distribution of index sarcoidosis patients, familial sarcoidosis patients, and a normal London population. more likely to be either Afro-Caribbean $(\mathrm{p}<0.001, \mathrm{RR}=3.76,95 \% \mathrm{CI}=3.04$ to 4.66$)$ or Asian $(\mathrm{p}<0.001, \mathrm{RR}=3.3,95 \% \mathrm{CI}=2.34$ to 4.66) when compared with a normal UK population (fig 1). Similar results were also reported when ethnic frequencies for patients with a family history of sarcoidosis were compared: Caucasian $(\mathrm{p}<0.001, \mathrm{RR}=0.15$, $95 \%$ CI $=0.09$ to 0.24 ), Afro-Caribbean $(\mathrm{p}<0.001, \mathrm{RR}=3.82,95 \% \mathrm{CI}=2.07$ to 7.05$)$, and Asian $(\mathrm{p}=0.0025, \mathrm{RR}=4.58,95 \% \mathrm{CI}=$ 1.74 to 12.08$)$.

The referral population to the Royal Brompton Hospital is not drawn from a random UK population but from the population of London, the ethnic distribution of which $(78 \%$ Caucasian, $10 \%$ combined Afro-Caribbean and Asian) differs somewhat from the rest of the UK (94\% Caucasian, 3.6\% combined AfroCaribbean and Asian). As this may lead to an inaccurate risk ratio, comparison was also made with the population of London (fig 2). Again, it was found that both index patients and those with a family history of the disease were more likely to be from the ethnic minority communities than from the Caucasian community.

Siblings of patients with sarcoidosis may themselves be at increased risk of the disease by virtue of their ethnicity. A comparison was therefore made of the ethnic distribution of both siblings and index patients but no significant difference was found. Finally, the prevalence of sarcoidosis for both familial and index Caucasian patients in this study was compared with previously published data on the prevalence of sarcoidosis in Caucasian patients for the London region. ${ }^{17}$ Again no significant difference was found (familial patients: $\mathrm{p}=$ 0.125 , index patients: $p=0.19)$.

\section{Discussion}

This study has shown that the relative risk of sarcoidosis in the families of an individual with sarcoidosis is of a level that would support the concept that common genetic determinants $( \pm$ common environmental determinants) predispose to this disease. Specifically, the $\lambda_{S}$ score is very supportive of this concept and is in agreement with previous studies that have explored this issue. ${ }^{18}$

It is interesting to note that the familial prevalence we have determined is 3-4 times greater than that previously reported from the UK. ${ }^{3}$ This may relate to differences in awareness of familial disease in both patients and their carers. However, this is unlikely to have resulted in any form of ascertainment bias. Theoretically, a relative of an individual who has been diagnosed as having sarcoidosis would be more likely to seek advice for symptoms that were similar to those of the index case. This would therefore possibly increase the rate of pick up of familial sarcoidosis. However, in this study the same would apply to individuals in whom there was no identification subsequently of a familial history and therefore this potential for ascertainment bias would be balanced. Furthermore, as a denominator for our $\lambda_{s}$ scoring we have used 
all the index cases approached and have presumed that those who did not reply had no familial incidents. This could lead to an overestimate of the risk ratio. By the same assumption, however, it is possible that there may have been more familial cases within the same cohort, thereby making our $\lambda_{\mathrm{s}}$ score an under-representation.

The second major finding of this study is that we were not able to confirm an increased risk of familial disease when account was taken for the variable prevalence of disease among the ethnic communities in the UK (Caucasian, AfroCaribbean, and Asian). It is well recognised that the disease has a different impact on individuals from different ethnic backgrounds. For example, erythema nodosum is a feature of acute disease and good prognosis is seen predominantly in young Caucasians while Lupus pernio and cutaneous manifestations of sarcoidosis (associated with chronic disease) appear more frequently in AfricanAmericans/Afro-Caribbeans. ${ }^{19}{ }^{20}$ In our study a 3-4 fold increased risk of developing sarcoidosis was observed in the Asian and AfroCaribbean communities compared with controls and this matched the increased familial risk.

The absence of a significant difference in ethnic distribution between familial and index sarcoidosis patients suggests that the ethnic breakdown in this group places them at increased risk per se of developing the disease, regardless of whether or not they are the sibling of an index case. This may also account for the familial sibling prevalence in our study group, which was higher than in the previous UK study conducted primarily in Caucasian subjects. ${ }^{3}$ However, when we compared the familial prevalence of sarcoidosis in our Caucasian subjects with previously published data for Caucasian subjects in a London population, no significant differences were observed.

These findings are in contrast with those of Rybicki et $a l^{10}$ who found that AfricanAmerican individuals were approximately three times more likely to have sarcoidosis than Caucasians in the USA. A second study by the same group involved an extensive survey of 1082 consecutive sarcoidosis patients, ${ }^{21} 14 \%$ of whom had evidence of familial sarcoidosis in first or second degree relatives. There was a threefold increase in familial sarcoidosis in African-Americans compared with Caucasians $(17 \%$ versus $6 \%)$. Although this difference between ethnic groups is similar to that observed in non-familial cases, when corrections were made for the difference in ethnic specific disease prevalence it was concluded that there was, indeed, heterogeneity in familial risk. Although these conclusions are at variance with ours, this may represent differences in analysis or numbers of families identified.

Families are likely to share common environments, infections, socioeconomic status, diet, and occupations in addition to genes. However, the increasingly accumulative evidence (monozygous/dizygous twin studies, ${ }^{3}$ racial predisposition to sarcoidosis, ${ }^{1021}$ and recent HLA studies, ${ }^{22}{ }^{23}$ ) supports the concept that genetic factors contribute to the development of sarcoidosis, both in the familial and non-familial context. This has important implications for future studies involving molecular epidemiology. With the increasing number of putative antigens being described, ${ }^{22-24}$ it may be possible in the near future to undertake a proper molecular epidemiological study of this disease and it is hoped that the ACCESS study from the USA will further inform this.

In conclusion, this study has shown that the familial risk of sarcoidosis appears to have increased in the UK over the last 25 years and supports the need for further studies into the genetic basis of this finding.

1 Newman LS. Beryllium disease and sarcoidosis: clinical and laboratory links. Sarcoidosis 1995;12:7-19.

2 Martenstein $\mathrm{H}$. Knochveranderungen bei Lupus pernio. Zentralb Haut Geschlechtskrankh 1923;7:308.

3 Scadding JG, Chapell AG, Sutherland I. Familial associations in sarcoidosis. Tubercle 1973;54:87-98.

4 Teirstein AS, Siltzbach LE, Berger H. Patterns of sarcoidosis in three population groups in New York. Ann NY Acad Sci 1976;278:371-6.

5 Brennan N, Crean P, Long JP, et al. High prevalence of familial sarcoidosis in an Irish population. Thorax 1984;39: $14-8$.

6 Wiman LG. In: Iwai K, Hosoda Y, eds. Proceedings of the VI International Conference on Sarcoidosis. Tokyo: University of Tokyo Press, 1974: 22-6.

7 Pietinalho A, Ohmichi M, Hirasawa $M$, et al. Familial sarcoidosis in Finland and Hokkaido, Japan: a comparative study. Respir Med 1999;93:408-12.

$8 \mathrm{McNicol}$ MW, Luce PJ. Sarcoidosis in a racially mixed community. $\mathcal{F} R$ Coll Physicians Lond 1985;19:179-83.

9 Harrington DW, Major M, Rybicki B, et al. Familial analysis of ninety one families. Sarcoidosis 1994;11:240-3.

10 Rybicki BA, Harrington D, Major M, et al. Heterogeneity of familial risk in sarcoidosis. Genet Epidemiol 1996;13:23-33.

11 Foley P, Lympany P, Puscinska E, et al. Analysis of MHC encoded antigen processing genes TAP1 and TAP2 polymorphisms in sarcoidosis. Am $\mathrm{f}$ Respir Crit Care Med 1999;160:1009-14.

12 Avila JJ, Lympany P, Pantelidis P, et al. Fibronectin gene polymorphisms associated with fibrosing alveolitis. $A m \mathcal{F}$ Respir Cell Mol Biol 1999;20:106-12.

13 Risch N. Linkage strategies for genetically complex traits. II. The power of affected relative pairs. Am $\mathscr{f}$ Hum Genet 1990;46:229-41.

14 Iannuzzi MC, Rybicki BA, Maliarik MJ, et al. Finding disease genes. From cystic fibrosis to sarcoidosis. Thomas A Neff lecture. Chest 1997;111:70-3S.

15 Todd JA. The Emperor's new genes: 1993 R D Lawrence lecture. Diabetic Med 1994;11:6-16.

16 Teirstein AS, Lesser M. Worldwide distribution and epidemiology of sarcoidosis. In: Fanburg B, ed. Sarcoidosis and other granulomatous lung diseases. Basel: Dekker, 1983: $101-34$

17 Edmonstone WM, Wilson AG. Sarcoidosis in Caucasians, Blacks and Asians in London. Br $\mathcal{F}$ Dis Chest 1985;79:2736.

18 Müller-Quernheim J. Sarcoidosis: immunopathogenetic concepts and their clinical application. Eur Respir $f$ 1998;12:716-38.

19 Löfgren S. Primary pulmonary sarcoidosis. Acta Med Scand 1953;145:424-65.

20 Rybicki BA, Major M, Popovich Jnr J, et al. Racial differences in sarcoidosis incidence: a five-year study in 145:234-41.

21 Harrington DW, Major M, Rybicki B, et al. Familial analysis of 91 families. Sarcoidosis 1994;11:240-3.

22 Berlin M, Fog-dell-Hahn A, Olerup O, et al. HLA-DR predicts the prognosis in Scandinavian patients with pulmonary sarcoidosis. Am $\mathcal{F}$ Respir Crit Care Med 1997;156: 1601-5.

23 Foley PJ, Fanning GC, Pantelides PP, et al. Association between HLA-DRB alleles and sarcoidosis. Thorax 1998; 53(Suppl 4):A60.

24 Tachibana T, Hiraga Y, Kunikane H, et al. HLA and familial sarcoidosis in Japan. Sarcoidosis 1992;9(Suppl 1):83-6. 